\title{
Letter
}

\section{Optimization of Turning Parameters to Minimize Burr by Using Taguchi Design Method}

\author{
Yanfei Bian*, Meng Cai, Shi Li, Shuai Zhang, Shengxuan Wu, Lichao Tong \\ The 54th Research Institute of China Electronics Technology Group Corporation, Shijiazhuang, China \\ Email address: \\ bianyfchengyy@163.com (Yanfei Bian) \\ *Corresponding author
}

\section{To cite this article:}

Yanfei Bian, Meng Cai, Shi Li, Shuai Zhang, Shengxuan Wu, Lichao Tong. Optimization of Turning Parameters to Minimize Burr by Using Taguchi Design Method. American Journal of Aerospace Engineering. Vol. 6, No. 1, 2019, pp. 11-16. doi: 10.11648/j.ajae.20190601.12

Received: July 9, 2019; Accepted: August 12, 2019; Published: September 2, 2019

\begin{abstract}
Reducing burr formation in machining operations is of vital importance as they can decrease the functionality of components and can cause injuries. Nowadays, additional processes for deburring are often necessary. To avoid deburring, the modification of turning processes is a promising approach. Here, different parameters have a significant influence on burr formation. This paper presents the influence of cutting parameters like cutting speed, feed rate, depth of cut on the burr size of 5A06, 6061 and 6063 aluminum alloy during turning on CNC lathe. A plan of experiments based on Taguchi method has been used to acquire the data. An orthogonal array, signal to noise $(\mathrm{S} / \mathrm{N}$ ) ratio and analysis of variance (ANOVA) are employed to investigate machining characteristics using fine turning tool within the domain of experiments considered. Experimental runs were chosen following L9 orthogonal array of Taguchi. Analysis of variance was undertaken to find out the influence of process parameters on the response noted. Predicted values are finally checked for accuracy through a confirmation test. Confirmation tests have been carried out to predict the optimal setting of process parameters to validated the proposed method and obtained the values $0.024 \mathrm{~mm}, 0.006 \mathrm{~mm}$, and $0.009 \mathrm{~mm}$ for burr height of 5A06, 6061 and 6063 aluminum alloy respectively. In this paper, methods for burr minimization in various cutting processes are presented. Burr reduction strategies for turning of different materials are presented.
\end{abstract}

Keywords: Burr, Turning, Taguchi, Signal to Noise, Analysis of Variance

\section{Introduction}

The presence of burrs on the edges of parts is the cause of various problems in manufacturing. Consequently, the deburring processes are included in manufacturing. The additional deburring operations increase the production cost and these additional expenses may contribute up to $30 \%$ of the total product price [1-5]. Furthermore, deburring normally requires a significant amount of time. This, coupled with the deburring cost, increases as the amount of burrs rises [6-10]. The selection of an appropriate duburring method depends on the dimensions and the location of the burr. Thus burr sizes must be controlled for the optimal choice of a deburring process or cutting parameters for burr minimization. The metal cutting burr formation and control are studied by the scholars and engineering experts [11-14]. They got a series of research achievement, improved the metal cutting burr formation theory and putted the deburring technology into machining.

Wei Zhao et al. [13] studied the burr and deformation information of the top of secondary micro V-grooves (SMVGs) during the fly cutting process. A series of experiments was carried out to investigate the effect of cutting conditions on the quality of hierarchical micro-structures by the one-step cutting method. It was found that large burrs are formed with an increase of the cutting depth, feed rate, and spindle speed; the plastic deformations become serious with an increase of the cutting depth and feed rate, but are reduced with a decrease of spindle speed.

Longhua $\mathrm{Xu}$ et al. [14] studied the relationship between cutting parameters and tool life and height of the cutting burrs. A new differential evolution algorithm based on adaptive 
neuro fuzzy inference system (DE-ANFIS) as a multi-input and multi-output (MIMO) prediction model was introduced to estimate the tool life and height of the cutting burrs. It was found that the cutting speed and feed rate had the most effects on the tool life and height of cutting burrs, respectively.

This paper is devoted to the study of the burr formation process in turning. Turning is a comparatively simple machining operation. However, if we understand the burr formation mechanism in the simple case and can model it, then we can describe burr formation mechanism by applying reasonable assumptions to more complicated cases such as face milling and drilling. The paper considers the case of burr formation when tool is unworn. 5A06, 6061 and 6063 aluminum alloy are the widespread work materials which plastic properties are sufficient to allow complete burr formation in feed direction without brittle failure of a burr. These points determined the choice of turning parameters for the given experimental work.

\section{Experimentation as Per Taguchi Method}

The methodology proposed by Taguchi [15-17] is widely used to design experimental runs based on orthogonal array (OA). It provides quite a less number of experiments. The orthogonal array forms the basis for the experimental analysis in the Taguchi method and provides the facility to select a set of minimum experimental runs. Signal-to-noise $(\mathrm{S} / \mathrm{N})$ ratio is used in this method as a measure of performance. It is a logarithmic function of output desired and is the objective function to go in for optimization. The mean and the variability are taken into account by $\mathrm{S} / \mathrm{N}$ ratio. It is ratio of mean (signal) and standard deviation (noise). Quality characteristic of $\mathrm{S} / \mathrm{N}$ ratios used are: lower-the-better (LB), higher-the-better (HB) and nominal-the-best (NB). When S/N ratio is maximized, corresponding parameter combination becomes the optimal setting. For solving burr minimization problem, LB characteristic is to choose. Analysis of variance (ANOVA) [18-20] is performed next to evaluate significance of process parameters. Through observation of $\mathrm{S} / \mathrm{N}$ ratio and ANOVA, optimal set of process parameters is selected. A L9 orthogonal array has been considered, which is used to optimize the turning parameters using the $\mathrm{S} / \mathrm{N}$ ratio and ANOVA for turning of aluminum alloy and predicted results were nearer to the experimental results. A confirmatory experiment is carried out to justify the selection of optimal process parameter combination.

\section{Details of Experiment}

\subsection{Experimental Set-Up}

The experimental investigation presented here was carried out on a CNC lathe (Type: CTX310ecov1) under wet with soluble oil conditions. 5A06, 6061 and 6063 aluminum alloy rod were chosen for turning experiments. Rod had the size of $\Phi 20 \mathrm{~mm} \times 50 \mathrm{~mm}$. Fine turning tool (Type: WNMG080404-MU) was used in these experiments.

Although a burr size can be characterized by its thickness and height, in the present work, burr height is considered to characterize a burr in line with many other works reported earlier. Height of turning burr was measured using a Mitutoyo, Japan make vernier caliper. Measurement of burr height around a turning slot was made at four locations for each sample, and average of these was considered for the analysis. The workpiece material and detail of experimental conditions are listed in Table 1.

Table 1. Experimental conditions.

\begin{tabular}{ll}
\hline Material and parameter & Content \\
\hline Machine tool & CNC lathe (CTX310ecov1) \\
Cutting tool & Fine turning tool (WNMG080404-MU) \\
Workpiece material & $5 \mathrm{~A} 06,6061,6063$ \\
Cutting velocity & $1000 \mathrm{r} / \mathrm{min}, 2000 \mathrm{r} / \mathrm{min}, 3000 \mathrm{r} / \mathrm{min}$ \\
Feed & $0.05 \mathrm{~mm} / \mathrm{r}, 0.125 \mathrm{~mm} / \mathrm{r}, 0.2 \mathrm{~mm} / \mathrm{r}$ \\
Depth of cut & $0.2 \mathrm{~mm}, 0.6 \mathrm{~mm}, 1.0 \mathrm{~mm}$ \\
Cutting environment & Wet with soluble oil \\
\hline
\end{tabular}

\subsection{Designing for Experiments}

There are several factors (process variables) that can control burr size (response) in turning. However, through literature review, following three parameters are found to be quite important to control burr height- (A) cutting velocity, (B) feed and (C) depth of cut. These three factors are primarily considered in the present work. Table 2 shows design factors chosen and their levels. In the present work, response variable is burr height in turning aluminum alloy rob. Process parameters in turning are optimized with an objective to minimize burr height.

Table 2. Detail of design factors.

\begin{tabular}{lllll}
\hline \multirow{2}{*}{ Design factors } & Unit & Levels & & \\
\cline { 3 - 5 } & & $\mathbf{1}$ & $\mathbf{2}$ & 2000 \\
\hline Cutting velocity (A) & $\mathrm{r} / \mathrm{min}$ & 1000 & 3000 \\
Feed (B) & $\mathrm{mm} / \mathrm{r}$ & 0.05 & 0.125 & 0.6 \\
Depth of cut (C) & $\mathrm{mm}$ & 0.2 & 0.2 & 1.0 \\
\hline
\end{tabular}




\subsection{Designing for Experiments}

Following Taguchi method, an orthogonal array was chosen to lower experimental runs for determining optimal process parameters. In this experimental work, an L9 orthogonal array (needing 9 experimental runs) was chosen. Table 3 shows the orthogonal array in detail.

Table 3. Detail of L9 orthogonal array $(O A)$.

\begin{tabular}{llll}
\hline Trial No. & Cutting velocity (A) & Feed (B) & Depth of cut (C) \\
\hline 1 & 1 & 1 & 1 \\
2 & 1 & 2 & 2 \\
3 & 1 & 3 & 3 \\
4 & 2 & 1 & 2 \\
5 & 2 & 2 & 3 \\
6 & 2 & 3 & 1 \\
7 & 3 & 1 & 3 \\
8 & 3 & 2 & 1 \\
9
\end{tabular}

\section{Experimental Results and Discussion}

Plan of experiments of 5A06, 6061 and 6063 aluminum alloy based on Taguchi orthogonal array and observed responses are shown in Table 4, Table 5, and Table 6, respectively.

Table 4. Plan of experiments of 5 A06 aluminum alloy based on Taguchi orthogonal array and observed response.

\begin{tabular}{|c|c|c|c|c|}
\hline Trial No. & Cutting velocity (r/min) & Feed $(\mathrm{mm} / \mathbf{r})$ & Depth of cut (mm) & Burr height (mm) \\
\hline 1 & 1000 & 0.05 & 0.2 & 0.027 \\
\hline 2 & 1000 & 0.125 & 0.6 & 0.022 \\
\hline 3 & 1000 & 0.2 & 1.0 & 0.037 \\
\hline 4 & 2000 & 0.05 & 0.6 & 0.031 \\
\hline 5 & 2000 & 0.125 & 1.0 & 0.022 \\
\hline 6 & 2000 & 0.2 & 0.2 & 0.028 \\
\hline 7 & 3000 & 0.05 & 1.0 & 0.029 \\
\hline 9 & 3000 & 0.2 & 0.6 & 0.03 \\
\hline
\end{tabular}

Table 5. Plan of experiments of 6061 aluminum alloy based on Taguchi orthogonal array and observed response.

\begin{tabular}{lllll}
\hline Trial No. & Cutting velocity $(\mathbf{r} / \mathbf{m i n})$ & Feed $(\mathbf{m m} / \mathbf{r})$ & Depth of cut $(\mathbf{m m})$ & Burr height $(\mathbf{m m})$ \\
\hline 1 & 1000 & 0.05 & 0.2 & 0.042 \\
2 & 1000 & 0.125 & 0.6 & 0.022 \\
3 & 1000 & 0.2 & 1.0 & 0.027 \\
4 & 2000 & 0.05 & 0.6 & 0.012 \\
5 & 2000 & 0.125 & 1.0 & 0.02 \\
6 & 2000 & 0.2 & 0.2 & 0.01 \\
7 & 3000 & 0.05 & 1.0 & 0.008 \\
8 & 3000 & 0.125 & 0.2 & 0.015 \\
9 & 3000 & 0.2 & 0.6 & 0.007 \\
\hline
\end{tabular}

Table 6. Plan of experiments of 6063 aluminum alloy based on Taguchi orthogonal array and observed response.

\begin{tabular}{lllll}
\hline Trial No. & Cutting velocity $(\mathbf{r} / \mathbf{m i n})$ & Feed $(\mathbf{m m} / \mathbf{r})$ & Depth of cut $(\mathbf{m m})$ & Burr height $(\mathbf{m m})$ \\
\hline 1 & 1000 & 0.05 & 0.2 & 0.037 \\
2 & 1000 & 0.125 & 0.6 & 0.028 \\
3 & 1000 & 0.2 & 1.0 & 0.023 \\
4 & 2000 & 0.05 & 0.6 & 0.011 \\
5 & 2000 & 0.125 & 1.0 & 0.018 \\
6 & 2000 & 0.2 & 0.2 & 0.013 \\
7 & 3000 & 0.05 & 1.0 & 0.011 \\
8 & 3000 & 0.125 & 0.2 & 0.019 \\
9 & 3000 & 0.2 & 0.6 & 0.011 \\
\hline
\end{tabular}

In the Taguchi method, the term 'signal' represents the desirable value (mean) for the output characteristic and the term 'noise' represents the undesirable value (Standard Deviation) for the output characteristic. $\mathrm{S} / \mathrm{N}$ ratio used to measure the quality characteristic deviating from the desired value. The $\mathrm{S} / \mathrm{N}$ ratio $\eta=-10 \log$ (M.S.D), Where M.S.D is the mean square deviation for the output characteristic. The $\mathrm{S} / \mathrm{N}$ ratio table for observed responses is shown in Tables 7-9. 
From main effects plot of $\mathrm{S} / \mathrm{N}$ ratio, the optimum parameters combination of 5A06 aluminum alloy for burr height is $\mathrm{A} 3 \mathrm{~B} 2 \mathrm{C} 1$ corresponding to the largest values of $\mathrm{S} / \mathrm{N}$ ratio for all control parameters. From Table 7, it is observed that feed rate, depth of cut, cutting speed has the order of influence on burr height during turning of 5A06 aluminum alloy.

Table 7. Signal to noise ratios of 5 A06 aluminum alloy for smaller is better.

\begin{tabular}{llll}
\hline Level & Cutting velocity (r/min) & Feed (mm/r) & Depth of cut (mm) \\
\hline 1 & 31.05 & 30.77 & 32.00 \\
2 & 31.46 & 33.29 & 31.26 \\
3 & 31.59 & 30.05 & 30.85 \\
Delta & 0.53 & 3.24 & 1.15 \\
Rank & 3 & 1 & 2 \\
\hline
\end{tabular}

From main effects plot of $\mathrm{S} / \mathrm{N}$ ratio, the optimum parameters combination of 6061 aluminum alloy for burr height is A3B3C2 corresponding to the largest values of $\mathrm{S} / \mathrm{N}$ ratio for all control parameters. From Table 8 , it is observed that cutting speed, feed rate, depth of cut has the order of influence on burr height during turning of 6061 aluminum alloy.

Table 8. Signal to noise ratios of 6061 aluminum alloy for smaller is better.

\begin{tabular}{llll}
\hline Level & Cutting velocity (r/min) & Feed (mm/r) & Depth of cut (mm) \\
\hline 1 & 30.69 & 35.96 & 34.67 \\
2 & 37.47 & 34.54 & 38.22 \\
3 & 40.50 & 38.16 & 35.76 \\
Delta & 9.82 & 3.62 & 3.55 \\
Rank & 1 & 2 & 3 \\
\hline
\end{tabular}

From main effects plot of $\mathrm{S} / \mathrm{N}$ ratio, the optimum parameters combination of 6063 aluminum alloy for burr height is A3B3C2 corresponding to the largest values of $\mathrm{S} / \mathrm{N}$ ratio for all control parameters. From Table 9, it is observed that cutting speed, feed rate, depth of cut has the order of influence on burr height during turning of 6063 aluminum alloy.

Table 9. Signal to noise ratios of 6063 aluminum alloy for smaller is better.

\begin{tabular}{llll}
\hline Level & Cutting velocity (r/min) & Feed (mm/r) & Depth of cut (mm) \\
\hline 1 & 30.82 & 35.66 & 33.59 \\
2 & 37.26 & 33.46 & 36.47 \\
3 & 37.59 & 36.55 & 35.61 \\
Delta & 6.77 & 3.09 & 2.87 \\
Rank & 1 & 2 & 3 \\
\hline
\end{tabular}

The purpose of the analysis of variance (ANOVA) is to investigate which design parameters significantly affect the quality characteristic. Table 10 shows the results of ANOVA for burr height of 5A06 aluminum alloy, feed rate is the significant cutting parameters for affecting the burr height. Table 11 shows the results of ANOVA for burr height of 6061 aluminum alloy, cutting velocity is the significant cutting parameters for affecting the burr height. Table 12 shows the results of ANOVA for burr height of 6063 aluminum alloy, cutting velocity is the significant cutting parameters for affecting the burr height.

Table 10. Results of ANOVA for burr height of 5 A06 aluminum alloy.

\begin{tabular}{llllll}
\hline Symbol & Cutting parameters & DOF & SS & MS & F \\
\hline A & Cutting velocity & 2 & 0.4682 & 0.2341 & 0.31 \\
B & Feed & 2 & 17.3370 & 8.6685 & 11.48 \\
C & Depth of cut & 2 & 2.0300 & 1.0150 & unsignificant \\
Error & & 2 & 1.5102 & 0.7551 & significant \\
Total & & 8 & 21.3454 & & unsignificant \\
\hline
\end{tabular}

$\mathrm{F}_{\text {table }}$ at $95 \%$ confidence level is $\mathrm{F}_{0.05,2,8}=4.46, \mathrm{~F}_{\text {exp }} \geq \mathrm{F}_{\text {table }}$

Table 11. Results of ANOVA for burr height of 6061 aluminum alloy.

\begin{tabular}{llllll}
\hline Symbol & Cutting parameters & DOF & SS & MS & F \\
\hline A & Cutting velocity & 2 & 151.59 & 75.796 & 7.17 \\
B & Feed & 2 & 19.96 & 9.978 & 0.94 \\
C & Depth of cut & 2 & 19.85 & 9.923 & significant \\
Error & & 2 & 21.15 & 10.575 & \\
Total & & 8 & 212.55 & & unsignificant \\
\hline
\end{tabular}

$\mathrm{F}_{\text {table }}$ at $95 \%$ confidence level is $\mathrm{F}_{0.05,2,8}=4.46, \mathrm{~F}_{\text {exp }} \geq \mathrm{F}_{\text {table }}$ 
Table 12. Results of ANOVA for burr height of 6063 aluminum alloy.

\begin{tabular}{llllll}
\hline Symbol & Cutting parameters & DOF & SS & MS & F \\
\hline A & Cutting velocity & 2 & 87.459 & 43.73 & 18.12 \\
B & Feed & 2 & 15.217 & 7.608 & 3.15 \\
C & Depth of cut & 2 & 13.055 & 6.527 & 2.70 \\
Error & & 2 & 4.828 & 2.414 & unsignificant \\
Total & & 8 & 120.558 & & \\
\hline
\end{tabular}

$\mathrm{F}_{\text {table }}$ at $95 \%$ confidence level is $\mathrm{F}_{0.05,2,8}=4.46, \mathrm{~F}_{\text {exp }} \geq \mathrm{F}_{\text {table }}$

Confirmatory experiments were conducted for burr size corresponding their optimal setting of process parameters to validate the used approach and obtained the values of 0.024 $\mathrm{mm}, 0.006 \mathrm{~mm}$ and $0.009 \mathrm{~mm}$ for burr height of 5A06, 6061 and 6063 aluminum alloy respectively. Predicted and experimental values of responses are depicted in table 13 .

Table 13. Optimal values of individual machining characteristics.

\begin{tabular}{|c|c|c|c|c|}
\hline Materials & Optimal combination of parameters & Significant parameters (at $95 \%$ confidence level) & Predicted optimum value & Experimental value \\
\hline $5 \mathrm{~A} 06$ & A3B2C1 & $\mathrm{B}$ & 0.024 & 0.021 \\
\hline 6061 & $\mathrm{~A} 3 \mathrm{~B} 3 \mathrm{C} 2$ & A & 0.006 & 0.007 \\
\hline 6061 & $\mathrm{~A} 3 \mathrm{~B} 3 \mathrm{C} 2$ & A & 0.009 & 0.011 \\
\hline
\end{tabular}

\section{Conclusion}

The machining characteristics of 5A06,6061 and 6063 aluminium alloy have been studied. The primary machining characteristics such as burr height was studied for turning. The results obtained from the experiments as follows.

From $\mathrm{S} / \mathrm{N}$ ratio response graph of $5 \mathrm{~A} 06$ aluminum alloy, the combination of parameters having the values of $3000 \mathrm{r} / \mathrm{min}$, $0.125 \mathrm{~mm} / \mathrm{r}, 0.2 \mathrm{~mm}$ obtained for cutting speed, feed rate, depth of cut respectively for optimizing burr size. From the results of ANOVA, feed rate is significant for all response.

From $\mathrm{S} / \mathrm{N}$ ratio response graph of 6061 aluminum alloy, the combination of parameters having the values of $3000 \mathrm{r} / \mathrm{min}$, $0.2 \mathrm{~mm} / \mathrm{r}, 0.6 \mathrm{~mm}$ obtained for cutting speed, feed rate, depth of cut respectively for optimizing burr size. From the results of ANOVA, cutting speed is significant for all response.

From $\mathrm{S} / \mathrm{N}$ ratio response graph of 6063 aluminum alloy, the combination of parameters having the values of $3000 \mathrm{r} / \mathrm{min}$, $0.2 \mathrm{~mm} / \mathrm{r}, 0.6 \mathrm{~mm}$ obtained for cutting speed, feed rate, depth of cut respectively for optimizing burr size. From the results of ANOVA, cutting speed is significant for all response.

From this study, a few general tendencies can be extracted in burr minimization strategy. These are:

A. Decrease of feed rate during turning process for 5A06 aluminum alloy;

B. Increase of cutting speed during turning process for 6061 and 6063 aluminum alloy.

The investigated mechanisms of burr formation are probably common for all materials which plastic properties are similar to those of aluminum alloy 5A06, 6061 and 6063. Further studies should be focused on the search for optimal tool geometry that can effectively minimize burr size or prevent its formation altogether and satisfy the limitations of tool performance. The results of this research will also be useful for subsequent studies and for the modeling of burr formation mechanism in feed direction for milling and drilling in order to find optimum conditions where burr dimensions can be predicted and controlled.

\section{References}

[1] Andrey Toropov, Sung-Lim Ko, Byung-Kwon Kim (2005) Experimental study of burrs formed in feed direction when turning aluminium alloy Al6061-T6. International Journal of Machine Tools \& Manufacture, 45: 1015-1022.

[2] Zhijie Zou, Liangwei Liu, Binglin Li, Wenjun Deng (2016) Research on burr formation mechanism in metal cutting with a backup material. Int J Adv Manuf Technol, 86: 1895-1907.

[3] Hashimura M., Chang Y. P., Dornfeld D. A. (1999) Analysis of burr formation mechanism in orthogonal cutting. Journal of Manufacturing Science and Engineering, 121: 1-7.

[4] Chern G. L. (2006) Study on mechanisms of burr formation and edge breakout near the exit of orthogonal cutting. J Mater Process Technol, 176: 152-157.

[5] Avinash A. Thakre, Shashank Soni (2016) Modeling of burr size in drilling of aluminium silicon carbide composites using response surface methodology. Engineering Science and Technology, an International Journal, 19: 1199-1205.

[6] Gongyu Liu, Jiaqiang Dang, Yaofeng Chen, Dapeng Dong, Qinglong An (2019) Numerical and experimental investigation on grinding-induced exit burr formation. The International Journal of Advanced Manufacturing Technology, 103: 2331-2346.

[7] Juan Huang, Yunming Zhu, Qinfeng Li, Guicheng Wang (2014) Active control methods of cutting burr in precision and ultra-precision machining. Applied Mechanics and Materials, 494-495: 620-623.

[8] Henrik Persson, Mathias Agmell, Volodymyr Bushlya, Jan-Eric Stahl (2017) Experimental and numerical investigation of burr formation in intermittent turning of AISI 4140. 16th CIRP Conference on Modelling of Machining Operations, 58: 37-42.

[9] Jingui Huang, Juan Huang, Cheng Yang, Guicheng Wang (2014) Analysis of feed-direction burr formation in micro-turning. Applied Mechanics and Materials, 590: 299-303. 
[10] Reddy Sreenivasulu, Chalamalasetti SrinivasaRao (2018) Investigation of influence of drill geometry and thrust force during drilling of aluminium 2014 alloy on burr formation through design of experiments and nueral network. Technological Engineering, XV: 5-10.

[11] Muhammad Asad, Hassan Ijaz, Waqas Saleem, Abdullah S. B. Mahfouz, Zeshan Ahmad, Tarek Mabrouki (2019) Finite element analysis and statistical optimization of end-burr in turning AA2024. Metals, 9: 1-19.

[12] Balogun Aizebeoje Vincent, Isuamfon Friday Edem, Omonigho B. Otanocha (2018) Characterization of chip and burr formation at high speed machining of nitronic 33 steel alloys. International Journal of Engineering Research in Africa, 35: 125-133.

[13] Wei Zhao, Haitao Wang, Wei Chen (2019) Studying the effects of cutting parameters on burr formation and deformation of hierarchical micro-structures in ultra-precision raster milling. The International Journal of Advanced Manufacturing Technology, 101: 1133-1141.

[14] Longhua $\mathrm{Xu}$, Chuanzhen Huang, Rui Su, Hongtao Zhu, Hanlian Liu, Yue Liu, Chengwu Li, and Jun Wang (2019) Estimation of tool life and cutting burr in high speed milling of the compacted graphite iron by DE based adaptive neuro-fuzzy inference system. Mechanical Sciences, 10: 243-254.

[15] Yoomin Ahn, Seoung Hwan Lee (2017) Classification and prediction of burr formation in micro drilling of ductile metals. International Journal of Production Research, 55: 4833-4846.
[16] Rahul Patil, Sagar Shinde, Deepak Marla, Suhas Joshi (2016) Experimental analysis of burr formation in drilling of TI-6AL-4V alloy. International Journal of Mechatronics and Manufacturing Systems, 9: 237-253.

[17] Sanjib Kundu, Santanu Das, Partha Pratim Saha (2014) Optimization of drilling parameters to minimize burr by providing back-up support on aluminium alloy. 12th Golbal Congress on Manufacturing and Management, GCMM 2014, 97: 230-240.

[18] Yin Bu, Wenhe Liao, Wei Tian, Jianxin Shen, Jian Hu (2016) An analytical model for exit burrs in drilling of aluminium materials. Int J Adv Manuf Technol, 85: 2783-2796.

[19] Rajmohan T., Palanikumar K., Madhavan. (2012) Optimizing the Machining Parameters for Minimum Burr Height in Drilling of Hybrid Composites. International Conference on Modelling, Optimisation and Computing ICMOC 2012, 38: 56-65.

[20] C. Moganapriya, R. Rajasekar, K. Ponappa, R. Venkatesh, S. Jerome (2018) Influence of coating material and cutting parameters on surface roughness and material removal rate in turning process using Taguchi method. Materials Today: Proceedings, 5: 8532-8538. 